\title{
(D) Case for mandatory COVID-19 vaccinations for OPEN ACCESS workers in health and aged care settings: a guide for leaders
}

\author{
Erwin Loh $\odot{ }^{1,2}$ Sarah Michael, ${ }^{1}$ Rob Beetson, ${ }^{1}$ Annie Schmidt ${ }^{1}$
}

${ }^{1}$ Executive Leadership Team, St Vincent's Health Australia, Sydney, New South Wales, Australia

${ }^{2}$ School of Clinical Sciences at Monash Health, Monash University, Clayton, Victoria, Australia

Correspondence to

Professor Erwin Loh, St Vincent's Health Australia, Sydney, NSW

2010, Australia;

erwin.loh@monash.edu

Received 25 October 2021 Accepted 16 November 2021

\begin{abstract}
Background This brief paper provides an overview of the analysis in support of mandating COVID-19 vaccinations for all workers in health and aged care settings in Australia. Leaders of health and aged care organisations have a duty of care under work health and safety legislation to eliminate and/or control the risk of transmission of vaccine-preventable disease in their facilities, including COVID-19.

Methods Key issues that should be considered by healthcare leaders when mandating that all health and aged care workers be vaccinated against COVID-19 were analysed by executives from a large Australian national health and aged care provider and discussed in this paper.

Results This paper summarises the medical/scientific, ethical, legal, work health and safety, workers' compensation and industrial relations considerations when mandating COVID-19 vaccination for healthcare workers.

Conclusion Leaders of health and aged care organisations must provide a safe environment and workplace for all those who work for them, as well as for those who receive care or treatment at one of their facilities. It is hoped that this paper will assist leaders of healthcare organisations in making their own decisions during this time.
\end{abstract}

\section{INTRODUCTION}

This brief paper provides an overview of the analysis in support of mandating COVID-19 vaccinations for all workers in health and aged care settings in Australia. The transmission of vaccinepreventable diseases (VPDs) in heath, aged care, and the community has the potential to cause serious illness and avoidable deaths in patients, residents or clients, workers, and users of the health and aged care systems.

With increasing staff and community expectations related to health and aged care facilities providing a safe environment for staff, patients and residents, leaders of health service providers will need to decide whether they should mandate that COVID-19 vaccination is required for all workers, with workers defined as including employees, contractors (including visiting medical officers), students and volunteers.

Leaders of health and aged care organisations have a duty of care under work health and safety legislation to eliminate and/or control the risk of transmission of VPD in their facilities, including COVID-19. These leaders must also be role models and not only encourage vaccination, but be vaccinated themselves, in a public and visible manner.

The following issues should be considered by healthcare leaders when mandating that all health and aged care workers be vaccinated against COVID-19 in Australia, but the principles may be relevant in other jurisdictions.

\section{THE SCIENTIFIC/MEDICAL CONSIDERATIONS}

The Delta variant is highly transmissible, estimated to be about $60 \%$ more transmissible than the Alpha variant, ${ }^{1}$ which significantly elevates the amount of risk to workers in sectors like health and aged care. The current COVID-19 vaccines approved in Australia by the Therapeutic Goods Administration by Pfizer and AstraZeneca are safe and highly effective against the Delta variant in protecting recipients from severe illness, hospitalisation and death, as shown by recent phase 3 clinical trials. ${ }^{23}$ The risks of serious side effects from these vaccines are extremely rare-the risk of thrombosis with thrombocytopenia syndrome with the AstraZeneca vaccine is 3 in 100000 doses, ${ }^{4}$ and for myocarditis/ pericarditis with the Pfizer vaccine, it is 13.5 per million doses. ${ }^{5}$ A recent review in Cell confirmed that both the Pfizer and AstraZeneca vaccines were 95\% effective against severe disease with the Delta variant. ${ }^{6}$

Recent evidence suggests that fully vaccinated workers are also less likely to transmit the virus. A recent German study found nosocomial transmissions were reduced in healthcare workers, ${ }^{7}$ a US study found that fully vaccinated healthcare workers protected patients from hospital-acquired COVID $-19^{8}$ and a South Korean study found only four breakthrough infections among 8678 fully vaccinated healthcare workers. ${ }^{9}$ In addition, a new study found that vaccination may reduce transmission by showing that vaccination of healthcare workers is associated with a decrease in documented cases of COVID-19 among members of their households. ${ }^{10}$

\section{THE ETHICAL CONSIDERATIONS}

There are two sorts of ethical considerations for healthcare leaders to requiring vaccination against COVID-19 as a condition of employment in hospital and aged care settings. First, what arrangements are ethically reasonable, and second, who should make decisions about those arrangements? The decision is made on the understanding that: 
- Hospitals and aged care facilities have a responsibility to take due care of patients and residents, their staff and visitors.

- The Delta variant of COVID-19 is both highly infectious and life-threatening to people whose health is already compromised and/or who are elderly.

- COVID-19 vaccines are available.

- Mechanisms are available to assess staff who have an objection to being vaccinated-whether this is medical or non-medical.

- Conscientious objection should be permitted so long as it does not put patients, residents, staff or visitors at risk of harm.

- Conscientious objection ought to be compatible with the ethos and values of the organisation. For example, legitimate reasons for conscientious objection may include cultural reasons but would not include manifestly prejudiced, discriminatory or otherwise harmful beliefs.

\section{THE LEGAL CONSIDERATIONS}

Leaders of health and aged care organisations must be able to demonstrate that mandatory vaccination is necessary to be able to both manage its work, health and safety (WHS) duties, and balance discrimination and privacy law obligations. It can be considered reasonable at law for health and aged care organisations to introduce a workplace policy mandating COVID-19 vaccination. Reasonableness would be based on a thorough assessment of the safety obligations that apply to the organisation and the means in which those obligations can be met, the nature of the work and the workplace (healthcare and aged care facilities), vaccine availability and the extent of public interaction employees may have.

The key actions required to ensure a mandatory vaccination policy is implemented effectively include a proper WHS assessment; consultation with employees, safety representatives and unions; and the inclusion of appropriate exceptions/exclusions in the policy. It was clearly highlighted that the implementation of such a policy should in no way lead to the organisation lessening other means of employee protection related to the COVID-19 pandemic, such as the adequate provision of personal protective equipment, physical distancing and requirements not to attend the workplace if symptomatic or knowingly aware that a person has been in contact with the virus through any means.

The policy must also address how the organisation may deal with an employee's refusal to be vaccinated with medical objections being the most structured to deal with. In line with ethical advice, health and aged care organisations should not be seen to enforce a view on vaccination and should allow conscientious objection. However, it is reasonable to expect that the conscientious objection should be based on scientific fact and supported by appropriate evidence.

For example, a person espousing a view that COVID-19 vaccinations contain a $5 \mathrm{G}$ chip or are being used to create a new world order should be dealt with sensitively, but their objection may be dismissed as it does not meet the scientific or evidence test. Objections on religious grounds will need to be carefully and sensitively assessed and should be handled so as to not create an action in discrimination. Objections from vegans or people opposed to animal cruelty may be dismissed by demonstrating that vaccines do not contain egg products or any animal-derived ingredients (eg, People for the Ethical Treatment of Animals has released a statement indicating both Pfizer and AstraZeneca vaccines do not contain any animal ingredients). ${ }^{11}$

\section{THE WORK HEALTH AND SAFETY CONSIDERATIONS}

Under the workplace health and safety legislation in all jurisdictions, leaders of businesses are required to ensure the health and safety of workers and other people in the workplace. Organisations are required to eliminate hazards or reduce the associated risk to as low as is reasonably practicable.

Safe Work Australia has advised employers to consider the available control measures and how they will help manage the risks of COVID-19, including any available vaccines, taking into account available evidence. WorkSafe Victoria states that COVID-19 vaccination should be considered part of a broader range of controls to reduce the risk of exposure to coronavirus in the workplace, while SafeWork New South Wales considers vaccination a high order (most effective) risk control measure.

Based on its effectiveness, vaccination would be considered a reasonably practicable control measure given the high risk of COVID-19 to workers, patients and residents. Vaccinations are also an appropriate control measure given the nature of work performed in health and aged care facilities and the inability to maintain physical distancing.

\section{THE WORKERS' COMPENSATION CONSIDERATIONS}

Under the workers' compensation scheme, employees who contract COVID-19 in the course of their employment may be entitled to compensation for medical expenses and lost wages. If an employee subsequently died because of workplace-acquired COVID-19, then, through the workers' compensation scheme, any dependent family members may be entitled to a lump sum death benefit and ongoing weekly payments. Over the long term, workplace-acquired COVID-19 could result in a significant increase in workers' compensation premiums. Conversely, if an employee were to have a significant adverse reaction to a workplace-mandated vaccine, then they may also be entitled to workers' compensation benefits.

On 28 August 2021, the Australian Government introduced a no fault COVID-19 vaccine indemnity scheme. ${ }^{12}$ From 6 September, Australians who suffer injury and loss of income due to their COVID-19 vaccine will be able to register their intent to claim from the scheme, which will cover the costs of injuries above $\$ 5000$ due to a proven adverse reaction to a COVID-19 vaccination. The scheme will be backdated to February 2021 and provide Australians with an alternative, administrative option to seek compensation, rather than a complex and costly court process.

\section{The industrial relations consideration}

The Australian Fair Work Ombudsman (FWO) has recently published guidance which provides that employers can direct their employees to be vaccinated if the direction is lawful and reasonable. ${ }^{13}$ Whether a direction is lawful and reasonable will be fact dependent and needs to be assessed on a case-by-case basis. When undertaking this assessment, the FWO has provided the following general guidance which divides work into four broad tiers:

- Tier 1 work, where employees are required as part of their duties to interact with people with an increased risk of being infected with coronavirus (for example, employees working in hotel quarantine or border control).

- Tier 2 work, where employees are required to have close contact with people who are particularly vulnerable to the health impacts of coronavirus (for example, employees working in health or aged care). 
- Tier 3 work, where there is interaction or likely interaction between employees and other people such as customers, other employees or the public in the normal course of work (for example, stores providing essential goods and services).

- Tier 4 work, where employees have minimal face-to-face interaction as part of their normal employment duties (for example, a person working from home).

The FWO guidance indicates that an employer's mandatory vaccination direction to employees performing tier 1 or tier 2 work is more likely to be reasonable, given the increased risk of employees being infected with coronavirus, or giving coronavirus to a person who is particularly vulnerable to the health impacts of coronavirus. An employer's mandatory vaccination direction to employees performing tier 4 work is unlikely to be reasonable, given the limited risk of transmission of the coronavirus. ${ }^{9}$

For employees performing tier 3 work, where no community transmission of coronavirus has occurred for some time in the area where the employer is located, a direction to employees to be vaccinated is in most cases less likely to be reasonable. However, where community transmission of coronavirus is occurring in an area, and an employer is operating a workplace in that area that needs to remain open despite a lockdown, a direction to employees to receive a vaccination is more likely to be reasonable. ${ }^{9}$

Regardless of the tier or tiers which may apply to work performed by employees, the question of whether a direction is reasonable will always be fact dependent and needs to be assessed on a case-by-case basis. This will require taking into account all relevant factors applicable to the workplace, the employees and the nature of the work that they perform.

\section{CONCLUSION}

Leaders of health and aged care organisations must provide a safe environment and workplace for all those who work for them, as well as for those who receive care or treatment at one of their facilities. The management of a COVID-19 mandatory vaccination policy requires a significant amount of administrative support as well as coordination by the infection control and human resources professionals. It is hoped that this paper will assist leaders of healthcare organisations in making their own decisions during this time.

Twitter Erwin Loh @erwinloh

Contributors All authors contributed equally to the drafting and review of the article.
Funding The authors have not declared a specific grant for this research from any funding agency in the public, commercial or not-for-profit sectors.

Competing interests None declared.

Patient consent for publication Not required.

Ethics approval This study does not involve human participants.

Provenance and peer review Not commissioned; internally peer reviewed.

Open access This is an open access article distributed in accordance with the Creative Commons Attribution Non Commercial (CC BY-NC 4.0) license, which permits others to distribute, remix, adapt, build upon this work non-commercially, and license their derivative works on different terms, provided the original work is properly cited, appropriate credit is given, any changes made indicated, and the use is non-commercial. See: http://creativecommons.org/licenses/by-nc/4.0/.

ORCID iD

Erwin Loh http://orcid.org/0000-0001-7157-0826

\section{REFERENCES}

1 Del Rio C, Malani PN, Omer SB. Confronting the delta variant of SARS-CoV-2, summer 2021. JAMA 2021;326:1001-2.

2 Falsey AR, Sobieszczyk ME, Hirsch I, et al. Phase 3 safety and efficacy of AZD1222 (ChAdOx1 nCoV-19) Covid-19 vaccine. N Engl J Med 2021. doi:10.1056/ NEJMoa2105290. [Epub ahead of print: 29 Sep 2021].

3 Thomas SJ, Moreira ED, Kitchin N, et al. Safety and efficacy of the BNT162b2 mRNA Covid-19 vaccine through 6 months. N Engl J Med 2021:385:1761-73.

4 Maclntyre CR, Veness B, Berger D, et al. Thrombosis with Thrombocytopenia Syndrome (TTS) following AstraZeneca ChAdOx1 nCoV-19 (AZD1222) COVID-19 vaccination - A risk-benefit analysis for people $<60$ years in Australia. Vaccine 2021;39:4784-7.

5 Pepe S, Gregory AT, Denniss AR. Myocarditis, pericarditis and cardiomyopathy after COVID-19 vaccination. Heart Lung Circ 2021;30:1425-9.

6 Cevik M, Grubaugh ND, Iwasaki A, et al. COVID-19 vaccines: keeping pace with SARSCoV-2 variants. Cell 2021;184:5077-81.

7 Brehm TT, Thompson M, Ullrich F, et al. Low SARS-CoV-2 infection rates and high vaccine-induced immunity among German healthcare workers at the end of the third wave of the COVID-19 pandemic. Int J Hyg Environ Health 2021;238:113851.

8 Roberts SC, Aniskiewicz MJ, Choi SJ, et al. Correlation of healthcare worker vaccination with inpatient healthcare-associated coronavirus disease 2019 (COVID-19). Infect Control Hosp Epidemiol 2021:1-2.

9 Jung J, Sung H, Kim S-H. Covid-19 breakthrough infections in vaccinated health care workers. N Engl J Med 2021;385:1629-31.

10 Shah ASV, Gribben C, Bishop J, et al. Effect of vaccination on transmission of SARSCoV-2. N Engl J Med 2021;385:1718-20.

11 PETA Australia. Can vegans get a COVID-19 vaccine? Available: https://www.peta. org.au/living/vegans-get-COVID-19-vaccine/ [Accessed 29 Oct 2021].

12 The Hon Greg Hunt MP. No fault COVID-19 indemnity scheme. Available: https:// www.health.gov.au/ministers/the-hon-greg-hunt-mp/media/no-fault-COVID-19indemnity-scheme [Accessed 29 Oct 2021].

13 Fair Work Ombudsman. COVID-19 vaccinations: workplace rights and obligations. Available: https://coronavirus.fairwork.gov.au/coronavirus-and-australian-workplacelaws/COVID-19-vaccinations-and-the-workplace/COVID-19-vaccinations-workplacerights-and-obligations [Accessed 29 Oct 2021]. 